\title{
A FORMAÇÃO DE PROFESSORES PARA A EDUCAÇÃO INFANTIL E ANOS INICIAIS DO ENSINO FUNDAMENAL: PERMANENCIAS E RUPTURAS DECORRENTES DAS DINÂMICAS SOCIAIS E DA LEGISLAÇÃO DO MAGISTÉRIO
}

\author{
Sandra Regina Rodrigues do Amaral ${ }^{1}$ \\ Universidade Estadual de Londrina - UEL \\ sreginamaral@hotmail.com
}

\section{RESUMO}

Neste artigo apresentamos um breve exercício de historiografia abordando dispositivos legais, presentes na legislação brasileira e na história da educação sobre formação de professores, a partir de 1932, ano da criação dos Institutos de Educação. Buscamos identificar as permanências e rupturas presentes na legislação constitutiva da trajetória histórica da formação de professores para a Educação Infantil e Anos Iniciais do Ensino Fundamental no Brasil, estabelecendo uma reflexão sobre as tendências que têm direcionado as políticas educacionais para formação de professores da educação infantil e anos iniciais do Ensino Fundamental e buscando compreender as características sociais que estabeleceram, para cada período, uma visão específica de homem e sociedade.

Palavras-chave: História da Educação; Historiografia; Legislação do Magistério; Formação de Professores.

\section{TRAINING OF TEACHERS FOR EDUCATION AND CHILDREN'S EARLY YEARS OF EDUCATION FUNDAMENAL: CONTINITIES AND RUPTURES ARISING OUT OF THE DYNAMICS OF SOCIAL AND LEGISLATION MAGISTERIUM}

\begin{abstract}
This article presents a brief exercise of historiography dealing with legal provisions, present in the brazilian legislation and the history of education teacher training, from 1932, year of creation of the Institutes of Education. We seek to identify the continuities and ruptures present in the constitutive laws of the historical course of teacher training for early childhood education and early years of primary education in Brazil, establishing a reflection on the trends that have driven educational policies for teacher training in early childhood education and early years of elementary school and trying to understand the social characteristics that established for each period, a specific vision of man and society. Keywords: History of Education; Historiography; Legislation of the Magisterium; Teacher Training
\end{abstract}

\section{Introdução}

A formação de professores é um tema fortemente presente nos debates contemporâneos sobre a crise da educação no Brasil, ora sendo apontada como responsável pela inconsistência dos resultados de aprendizagem, por ser estruturada de modo fragmentado, desprovida da relação teoria-prática, ora emergindo como elemento estratégico a ser focado para que se implementem melhorias na educação. Kishimoto 
(2002), tece considerações sobre a fragmentação curricular dos cursos de formação de professores, estruturados sobre disciplinas que não dialogam entre si, o que dificulta a constituição de um profissional da educação que compreenda o desenvolvimento da aprendizagem da criança como um processo integrado.

A formação de professores é fator de importância irrestrita para a qualidade da educação e os cursos de formação devem pautar-se referencialmente por normas legais e recomendações pedagógicas, de modo que se encarreguem da preparação escolar formal e da constituição de cidadania. Mello (2000), amplia essa discussão, afirmando que, "entendida como componente estratégico da melhoria da qualidade da educação básica, a formação inicial de professores deve ser entendida como política pública, embora não seja necessário que o poder público a execute diretamente, é indispensável que ele estabeleça critérios de financiamento, padrões de qualidade e mecanismos de avaliação e acompanhamento".

Nesse sentido, estabelecemos um diálogo entre os textos legais e o referencial presente na historiografia sobre o tema, fazendo um exercício de compreender a formação de professores para os anos iniciais do ensino fundamental, considerando os contextos em que as políticas para a referida formação foram estruturadas e implementadas, na tentativa de identificar os pressupostos de cada contexto social e perceber as permanências e rupturas decorrentes das dinâmicas sociais e da legislação para o magistério que permeiam o estabelecimento (ou não), de políticas educacionais para a formação de professores.

\section{Políticas Educacionais para formação de professores: um olhar a partir de 1932}

A trajetória da problemática da formação de professores no Brasil, remonta ao século XIX, período no qual a mobilidade social favorecida pela nova ordem políticoeconômica, produz uma ruptura na estrutura dualista do sistema educacional brasileiro que apresentava de um lado o ensino primário, vinculado às escolas profissionalizantes para os pobres, e de outro, o ensino secundário articulado ao ensino superior, para os ricos. Embora, cronologicamente, conforme Saviani (2007), a formação de professores tenha um início anterior, somente a partir da universalização da instrução elementar e consequiente instituição dos sistemas nacionais de ensino, a formação de professores emerge como um problema.

A partir, porém, do século XIX, a necessidade de universalizar a instrução elementar conduziu à organização dos sistemas nacionais de ensino. Estes concebidos como um conjunto amplo constituído por um grande número de escolas organizadas segundo um mesmo padrão, se viram diante do problema de formar professores, também em grande escala, para atuar nas referidas escolas. e o caminho encontrado para equacionar essa questão foi a criação de escolas normais, de nível médio,para formar professores primários, atribuindo-se ao nível superior, a tarefa de formar os professores secundários (SAVIANI, 2007, p. 01).

Em 1932, Anísio Teixeira estrutura uma Reforma Educacional, legitimada pelo Decreto 3.810, de 19 de março de 1932, transformando a escola normal em escola de professores, buscando implementar na formação de professores, o modelo pedagógicodidático, marcado por um ensino de humanidades e ciências mais significativos.

Para esse fim transformou a Escola normal em Escola de Professores, 
cujo currículo incluía, já no primeiro ano, as seguintes disciplinas: 1) biologia educacional; 2) sociologia educacional; 3) psicologia educacional; 4) história da educação; 5) introdução ao ensino, contemplando três aspectos: a) princípios e técnicas; b) matérias de ensino abrangendo cálculo, leitura e linguagem, literatura infantil, estudos sociais e ciências naturais; c) prática de ensino, realizada mediante a observação, a experimentação e a participação. Como suporte ao caráter prático do processo formativo, a Escola de Professores contava com uma estrutura de apoio que envolvia: a) Jardim de Infância, Escola Primária e Escola Secundária, que funcionavam como campo de experimentação, demonstração e prática de ensino; b) Instituto de Pesquisas Educacionais; c) Biblioteca Central de Educação; d) Bibliotecas escolares; e) Filmoteca; f) Museus Escolares; g) Radiodifusão (SAVIANI, 2007, p. 06)

Em 1.939, o Decreto-Lei ${ }^{\circ} 1.190$, de 04 de abril organiza a Faculdade Nacional de Filosofia da Universidade do Brasil, escola de referência para as demais escolas de nível superior. O paradigma resultante do Decreto-Lei 1.190 se estendeu para todo o país, compondo o modelo que ficou conhecido como esquema três mais um, adotado na organização dos Cursos de Licenciatura e de Pedagogia. Os primeiros formavam os professores para ministrar as várias disciplinas que compunham os currículos das escolas secundárias. Os segundos formavam os professores para exercer a docência nas escolas normais. Em ambos os casos vigorava o mesmo esquema, isto é, três anos para o estudo das disciplinas específicas, vale dizer, os conteúdos cognitivos ou os cursos de matérias, na expressão de Anísio Teixeira; e um ano para a formação didática (SAVIANI, 2007, p. 06)

Anos após, em 1.946, o ensino normal é reestruturado. Na nova estrutura o Curso Normal, em simetria com os demais cursos de nível secundário, foi dividido em dois ciclos: o primeiro correspondia ao ciclo ginasial do curso secundário e tinha a duração de quatro anos. Seu objetivo era formar regentes do ensino primário e funcionaria em Escolas Normais Regionais. O segundo ciclo, com a duração de três anos, correspondia ao ciclo colegial do curso secundário. Seu objetivo era formar os professores do ensino primário e funcionaria em Escolas Normais e nos Institutos de Educação. Estes, além dos cursos citados, contariam com Jardim de Infância e Escola Primária anexos e ministrariam também cursos de especialização de professores primários para as áreas de educação especial, ensino supletivo, desenho e artes aplicadas, música e canto e cursos de administradores escolares para formar diretores, orientadores e inspetores escolares.

Paralelamente às discussões e reformas pedagógicas, discussões sobre Políticas Educacionais foram sendo desenvolvidas e, em 1.948, Clemente Mariani Bittencourt, Ministro da Educação, propôs um anteprojeto da primeira Lei de Diretrizes e Bases da Educação Nacional. O projeto foi discutido por treze anos e originou a Lei 4.024, promulgada em 20 de dezembro de 1.961. A lei foi o primeiro documento sobre as diretrizes da educação para o país e estava marcadamente impregnada pelo espírito do liberalismo, já destacando no primeiro artigo, a defesa da liberdade individual e intelectual, preconizada pelos fins da educação constantes dos princípios de liberdade e ideais de solidariedade humana: a) a compreensão dos direitos e deveres da pessoa humana, do cidadão, do Estado, da família e dos demais grupos que compõe a comunidade; b) o respeito à dignidade e às liberdades fundamentais do homem; c) o fortalecimento da unidade nacional e da solidariedade internacional; d) o desenvolvimento integral da personalidade humana e a sua participação na obra do bem comum; e) o preparo do indivíduo e da sociedade para o domínio dos recursos científicos e tecnológicos que lhes 
permitam utilizar as possibilidades e vencer as dificuldades do meio; f) a preservação e expansão do patrimônio cultural; g) a condenação a qualquer tratamento desigual por motivo de convicção filosófica, política ou religiosa, bem como a quaisquer preconceitos de classe ou de raça.

A primeira LDB brasileira normatiza a formação do Magistério para o Ensino Primário e Médio. Destacamos que, no texto da Lei 4.024/61, está posto como ensino médio ou educação de grau médio, aquela que dá prosseguimento à ministrada na escola primária, destinada à formação de adolescentes, sendo ministrada em dois ciclos, o ginasial e o colegial, abrangendo entre outros, os cursos secundários, técnicos e de formação de professores para o ensino primário e pré-primário.

A finalidade da formação de professores, orientadores, supervisores e administradores escolares, colocada pela Lei 4.024/61 é o desenvolvimento dos conhecimentos técnicos relativos à educação da infância. A formação de professores para o nível primário se dá, conforme a lei, em escola normal de grau ginasial, (com, no mínimo quatro séries anuais, constando disciplinas obrigatórias do curso secundário e disciplinas pedagógicas) e grau colegial (com, no mínimo três séries, em prosseguimento ao grau ginasial). A primeira para expedição do diploma de regente de ensino primário e a segunda, de professor primário. A formação de professores para o ensino médio ocorre, em atendimento à mesma lei, nas faculdades de filosofia, ciências e letras e a de professores de disciplinas específicas de ensino médio técnico em cursos especiais de educação técnica. No capítulo que trata de formação e professores não há menção à formação de professores para o ensino superior.

Com o advento do Regime Militar, em 1.964, as normas orientadoras da educação foram sofrendo alterações dentre as quais se destacam aquelas propostas pelo Decreto 63.914, de 27/12/1968, responsável pela criação do PREMEN - Programa de Expansão e Melhoria do Ensino. O programa pretendia formar professores com as finalidades de atender às necessidades de ampliação da oferta de matrícula na área do ensino médio e propor alternativas de reformulação da estrutura da escola média, através da implementação, em larga escala, de um modelo novo de escola de $1^{\circ}$ Ciclo (DALBEN, 2004). As escolas polivalentes, criadas pelo Programa, seguiam os moldes da educação norte americana, tendo a função de promover a melhoria e a expansão do ensino, tendo como foco a educação técnica.

Em 1.971, em meio ao "milagre econômico brasileiro",2 é promulgada a Lei 5.692, cuja característica mais marcante foi imprimir um cunho profissionalizante na formação educacional. A lei, de caráter anti-democrático e tecnicista, foi elaborada por um grupo de trabalho indicado pelo Presidente da República, Emílio Garrastazu Médici, que a estruturou num prazo de sessenta dias, de acordo com as finalidades estabelecidas pela presidência da república para a educação.

A principal tarefa do GT era reformular os cursos de $1^{\circ}$ e $2^{\circ}$ graus, nova nomenclatura posta pela lei, já que pela lei anterior, os cursos eram de ensino primário e médio. Em relação à formação de professores, são extintas as Escolas Normais, sendo instituída em seu lugar, a Habilitação Específica de $2^{\circ}$ grau para o exercício do magistério de $1^{\circ}$ grau (HEM). As contribuições da Lei 5.692/71, não foram ao encontro da melhoria no processo de formação dos professores, de acordo com Saviani ( 2007), o que houve, na realidade foi a precarização do processo de formação de professores uma vez que a docência para $1^{\mathrm{a}}$ a $4^{\mathrm{a}}$ séries foi reduzida a uma habilitação dispersa em meio a tantas outras.

O momento social pós redemocratização do país, ocorrido a partir do fim do Regime Militar impõe a sociedade a busca pela abertura política, que reflete, no âmbito da 
escola, num movimento pela democratização do ensino; surgem os colegiados, a eleição de diretores, são criados espaços para o debate sobre educação, como a ANPED ( Associação Nacional de Pós-Graduação e Pesquisa em Educação), ENDIPE ( Encontro Nacional de Didática e Prática de Ensino) e ANPAE (Associação Nacional de Política e Administração da Educação) e estruturadas as bases para os Projetos Políticos Pedagógicos Escolares.Nesse contexto, a sociedade se mobiliza pela elaboração de um Plano Nacional de Educação constituído a partir dos anseios da sociedade brasileira. Um plano que refletisse um projeto democrático e popular, reivindicando o fortalecimento da escola pública estatal e a plena democratização da gestão educacional, como eixo do esforço para se universalizar a educação básica. Isso, apontado por Valente e Romano (2002), implicaria propor objetivos, metas e meios audaciosos.

O governo aprova o plano e o sanciona com nove vetos, em 9 de janeiro de 2001, Lei $\mathrm{n}^{\mathrm{o}} 10.172 / 2001$. O plano, descaracterizado pelos vetos, constitui-se, como afirma Valente e Romano (2002) em uma carta de intenções, não conseguindo implementar em nível nacional, o que se pretendia pela sociedade ao estabelecer as metas do plano. Paralelamente ao Plano Nacional de Educação da sociedade, tramitou no Congresso um substitutivo, apresentado pelo então Senador Darci Ribeiro, aprovado como a Lei 9.394/96, atual Lei de Diretrizes e Bases da Educação Nacional. De acordo com Saviani ( 2008) , a nova lei introduziu como alternativa aos cursos de pedagogia e licenciatura os Institutos Superiores de Educação e as Escolas Normais Superiores, a LDB sinalizou para uma política educacional tendente a efetuar um nivelamento por baixo: os Institutos Superiores de Educação emergem como instituições de nível superior de segunda categoria, provendo uma formação mais aligeirada, mais barata, por meio de cursos de curta duração.

A nova LDB, Lei 9.394/96 redefine o lugar da União na organização da Educação Nacional, o Estado passa a articular os diferentes níveis e sistemas de ensino e exercer as funções normativa, redistributiva e supletiva em relação às outras instâncias educacionais, garantindo liberdade aos sistemas de ensino e atribuindo um caráter minimalista ao Estado, frente à educação do país. Com a criação dos Institutos Superiores de Educação, que podem ou não estar vinculado às universidades, a Lei 9.394/96 estimula a proliferação, por todo o país, de escolas de qualidade questionável, mantidas pela iniciativa privada, nos diferentes níveis de ensino, especialmente na formação de professores. Para Kuenzer (1998), ao se retirar das Universidades a responsabilidade da formação dos professores, o ensino superior é elitizado, retirando da formação de professores, o caráter rigoroso da qualificação científica e da apropriação de metodologias adequadas à produção de conhecimento em educação.

\section{Dinâmicas sociais e políticas constitutivas da historiografia da formação de professores no Brasil a partir de 1.932}

As tendências educacionais balizadoras da formação de professores, assim como toda política pública, não estão desvinculadas da concepção de homem, mundo e sociedade que se pretende constituir para um determinado tempo, não sendo possível desvincular essa formação dos contextos sociais sobre a organização do trabalho na sociedade capitalista. Assim, verifica-se uma teoria tradicionalista de educação para os primórdios da educação no Brasil, vinculada ao contexto "civilizatório" do período colonial; a continuidade da educação tradicional durante o Período Imperial e Início do Período Republicano, vinculada ao positivismo e ao forte propósito de formar alunos para o ensino superior; a convivência transitória entre a pedagogia tradicional e a pedagogia nova durante o Período 
Republicano, que logo cedeu lugar ao tecnicismo, no período militar, na intenção de preparar trabalhadores para o mercado e, finalmente como retorno da democratização no país, após o período de ditadura militar, sob a influência do neoliberalismo, a assunção de caráter minimalista às ações do Estado e a atribuição à Educação de um caráter mercadológico. Cada período histórico, na dinâmica de seus contextos, estabeleceu um modelo de educação, que previa também um professor, capaz de preparar os homens para a sociedade que se pretendia, de acordo com as ideologias hegemônicas.

\subsection{Décadas de 1.930 e 1.940: a ditadura do Estado Novo e a Escola Nova}

$\mathrm{Na}$ década de 1.920, período do pós-guerra,o imperialismo americano iniciou sua influência nos países da América Latina, Àsia e África. Influência que deu-se no campo econômico, evoluindo para o campo cultural e educacional,disseminando o ideário pedagógico da Escola Nova, que se estendeu pelas próximas duas décadas.

Em suma, é possível dizer que a Primeira República se caracterizou por manter uma estrutura social marcada pelo ruralismo, com uma industrialização forjada e subjugada pela reorganização capitalista da cafeicultura. No plano político, manteve os industriais como meros parceiros secundários das oligarquias $\mathrm{n}$ interior dos PRs (Partidos Republicanos Estaduais), apoiando a manutenção da política do "café com leite" e o modelo econômico agrário-exportador-dependente. No âmbito pedagógico esse período consolidou a Pedagogia Tradicional, sufocou a organização da Pedagogia Socialista e da Pedagogia Libertária e assistiu o advento da Pedagogia Nova (GHIRALDELLI, 1987, p. 30)

A década de 1.930, foi marcada por tensões entre a direita, representada pela Ação Integralista Brasileira e a esquerda, representada pela Aliança Nacional Libertadora ${ }^{3}$. O governo Vargas, conforme aponta Ghiraldelli (1987), transitava entre as duas ideologias, buscando estabelecer uma política autônoma, focada numa linha trabalhista, que tinha como objetivo central a cooptação dos trabalhadores através de medidas paternalistas e do incentivo ao sindicalismo corporativista.

$\mathrm{Na}$ educação foram sendo adotadas medidas para retirar o caráter propedêutico da formação de professores, estabelecendo uma formação basicamente profissional. Com esse objetivo, o antigo ciclo preparatório da escola normal é ampliado e equiparado ao ensino secundário federal - curso fundamental, de cinco anos - enquanto o curso profissional, totalmente reformulado, veio a constituir a escola de professores.

No final da década de 1.930, até meados da década de 1.940, a orientação centralizadora estadonovista ${ }^{4}$ regulamenta a Escola Normal e o ensino no país, de forma geral, mediante Leis Orgânicas do ensino.

Em simetria com as demais modalidades de ensino de segundo grau, o Normal foi dividido em dois ciclos: o primeiro fornecia o curso de formação de "regentes" do ensino primário, em quatro anos, e funcionaria em Escolas Normais Regionais; o curso de segundo ciclo, em dois anos, formaria o professor primário e era ministrado nas Escolas Normais e nos Institutos de Educação. Além dos referidos cursos, os Institutos de Educação deveriam ministrar os cursos de especialização de professores para a educação especial, curso complementar primário, ensino supletivo, desenho e artes aplicadas, música e canto - bem como cursos de 
administradores escolares, para habilitar diretores, orientadores e inspetores (TANURI, 2000, p. 75-76).

A existência de dois cursos diferentes com objetivos similares: formação de regentes e formação de professores primários, se justificava pelas diferenças de ordem econômica e cultural que coexistiam nos diferentes estados da federação.

De acordo com Ghiraldelli (1987), o regime ditatorial do Estado Novo foi um divisor de águas no campo político e no campo da legislação educacional. Educadores considerados da vanguarda escolanovista como Anísio Teixeira e Paschoal Leme se afastaram do governo do Estado Novo, por buscarem como meta o regime democrático, entretanto outros, como Lourenço Filho e Fernando de Azevedo, entusiastas do governo "forte e centralizador", apoiaram as medidas políticas e educacionais. Tanto uns, quanto outros, se comprometiam com a teoria liberal da neutralidade da educação e da pedagogia, pressupostos da Pedagogia da Escola Nova.

\subsection{Décadas de 1.950 e 1.960: o nacionalismo desenvolvimentista e a Pedagogia Libertadora}

A industrialização iniciada no final da década de 1.940, foi acelerada e acentuada na década de 1.950, levando a população urbana a superar, em termos numéricos, a população rural. A industrialização, nesse período, foi sustentada basicamente, pela participação do capital internacional no país. Em função do crescimento das cidades, o campo também sofreu um processo intenso de transformação que traduziu-se na retirada do homem do campo e no surgimento de um novo trabalhador no processo produtivo da sociedade: o bóia-fria. O país passou por um processo de redemocratização, que, conforme exemplifica Ghiraldelli (1987), levou ao surgimento de três grandes partidos que dominaram a cena político-partidária da época: a UDN (União Democrática Nacional), o PTB ( Partido Trabalhista Brasileiro) e o PSD ( Partido Social Democrático).

O PTB e o PSD, apoiados por Vargas, buscavam a continuidade das políticas trabalhistas e controle dos movimentos sociais do proletariado urbano. A UDN, antigetulista, defendia a aliança com o capital estrangeiro como suporte da industrialização controlada pelo Estado Nacional.

Nesse contexto, tramitava o projeto da Lei de Diretrizes e Bases da Educação Nacional, que seria aprovado, em 1.961 sob o número 4.024/61. A tramitação estava impregnada das discussões entre a esquerda e direita que haviam se aliado à burguesia industrial através do nacionalismo-desenvolvimentista, que tinha como objetivos principais a proteção cambial da indústria nacional, facilidades do Estado para importação de equipamentos e a transferência de lucros da agricultura para a indústria. Ghiraldelli (1987), apresenta que a aliança era bastante frágil, pois os industriais a rejeitavam, quando tratavase de nacionalização de empresas estrangeiras ou de exercer um controle sobre a remessa de lucros para o exterior.

No bojo da industrialização, vieram as pressões da esquerda pela democratização da sociedade e melhor distribuição de renda, o que pressupunha reformas de base na área educacional. A escola foi convocada a participar dessa reforma, passando-se à discussão da Pedagogia Renovada. Essas discussões levaram à criação de classes e escolas experimentais, que buscam desenvolver boas experiências em educação, que pudessem dar suporte à renovação do ensino no país. Esse período foi pródigo em movimentos sociais populares que foram se afirmando e estabelecendo um tipo de Escola Nova Popular, que traduziu-se na Pedagogia Libertadora. 
No que concerne à formação de professores, a Lei de Diretrizes e Bases da Educação Nacional - LDB 4.024/61 não contribuiu com inovações.

A Lei de Diretrizes e Bases da Educação Nacional (Lei 4.024, de 20/12/1961) não trouxe soluções inovadoras para o ensino normal, conservando as grandes linhas da organização anterior, seja em termos de duração dos estudos ou de divisão em ciclos. Registre-se apenas a equivalência legal de todas as modalidades de ensino médio, bem como a descentralização administrativa e a flexibilidade curricular, que possibilitariam o rompimento da uniformidade curricular das escolas normais. As reformas estaduais das escolas normais, com vistas a ajustá-las à nova Lei, limitaram-se principalmente a alterações curriculares. A maioria dos estados conservou o sistema dual, com escolas normais de nível ginasial, com quatro séries no mínimo, e as de nível colegial, com três séries no mínimo, certamente em face da insuficiente quantidade de candidatos qualificados para a docência no ensino primário (TANURI, 2000, p. 78).

São desse período, os primeiros pareceres favoráveis à formação, em nível superior, para os professores primários. Os pareceres 251/62 e 252/62 do Conselho Federal de Educação já apontam para a direção da Formação em Pedagogia como condição para o professor trabalhar no ensino primário, embora essa alteração só fosse efetivar-se por volta das décadas de 1.980 e 1.990 , mediante alterações na programação dos cursos de Pedagogia.

Uma das maiores alterações para o período, em termos de formação profissional, não foi um avanço, mas o retorno das disciplinas de formação geral no currículo do curso normal, elevando o nível de formação do professor.

Em decorrência dos dispositivos da LDB pertinentes ao núcleo comum de currículo, obrigatório a todos os cursos médios, disciplinas de formação geral voltaram a ser introduzidas no curso normal, de modo a continuar o processo de elevação do nível de formação do futuro professor. Ademais, com a atribuição aos Conselhos Estaduais de fixar disciplinas complementares e arrolar optativas a serem escolhidas pelos estabelecimentos de ensino, há um crescimento do número de disciplinas de formação técnico-pedagógica nos currículos das escolas normais (...). Da mesma forma que nos currículos anteriores, continuava a haver um certo distanciamento em relação à realidade social e educacional, resultante não somente da ausência de disciplinas voltadas para a análise das questões educacionais brasileiras, como também do tratamento científico, universal, "neutro" dos demais componentes (TANURI, 2000, p. 79).

O foco passou dos conteúdos para as metodologias. Para a formação de professores foi estabelecida uma maior preocupação sobre a prática docente, sobre a operacionalização dos objetivos educacionais em termos de aprendizagens e comportamentos. Buscava-se a eficiência escolar. Tratava-se de tornar a escola "eficiente e produtiva", ou seja, de torná-la operacional com vistas à preparação para o trabalho, para o desenvolvimento econômico do país, para a segurança nacional (TANURI, 2000, p.79)

No período pós 1.964, com a instituição do militarismo no país, a escola passou por um processo de adaptação. A Educação começou a ser vista como fator propício para o assistencialismo e para a difusão da nova ideologia oficial, que visava, antes de tudo, 
conforme Saviani (1984) "neutralizar os focos de subversão interna".

Estão postas as bases para a tendência pedagógica que viria a seguir, o tecnicismo.

\subsection{Década de 1970: Regime Militar e a Escola Tecnicista}

Com o advento do Regime Militar, em 1.964, o país passou por um período de extrema centralização e coerção, vivendo um período de desenvolvimentismo associado, no qual a economia tem base na indústria, sendo dependente do capital estrangeiro. Nesse contexto, o desenvolvimento não podia ser separado da "segurança": conforme afirma Hilsdorf (2003), de acordo com a doutrina que vinha sendo definida pela Escola Superior de Guerra, tanto a manutenção da ordem política, social e econômica vigente quanto o combate às ideologias estrangeiras - representadas pela ameaça comunista que objetivaria distanciar a sociedade brasileira de seus valores morais, religiosos e culturais tradicionais eram fatores de desenvolvimento.

$\mathrm{Na}$ área educacional foram implementadas políticas justificadas pela ótica do liberalismo de que somente o investimento na melhoria do "capital humano", , seria capaz de adequar a sociedade brasileira às exigências da produção internacional. A escola passou a ser acusada pelos tecnocratas, de acordo com Ghiraldelli (1987), como excessivamente politizada e de baixo rendimento, levando à propostas de modernização do Sistema Escolar. Na formação de professores, a ênfase passou a ocorrer nas áreas tecnológicas. A formação geral cedeu espaço a treinamento específico e as ciências sociais e humanidades foram perdendo espaço nos currículos escolares.

O foco sócio-educacional passou a ser a obtenção de rentabilidade com maior economia de recursos e a formação de pessoal para as empresas em expansão. Nesse sentido, buscava-se o apoio do capital internacional para as reformas que se pretendiam efetivar na área da educação.

Entre 1964 e 1968 foram assinados 12 acordos MEC-USAID, com a finalidade de diagnosticar e solucionar problemas da educação brasileira na linha do desenvolvimento internacional baseado no "capital humano". Os assessores da USAID agiam segundo uma evidente mentalidade empresarial, que, combinada às medidas de exceção da área militar, deu as marcas da política educacional do período: desenvolvimentismo, produtividade, eficiência, controle e repressão (HILSDORF, 2003, p. 124).

Conforme Saviani (1984), a Lei 5.540/68 que reformou o ensino superior e a Lei $5.692 / 71$, que reformou os ensinos de primeiro e segundo graus trouxeram grandes diferenciações, se comparadas à lei anterior, 4.024/61: o foco foi transposto da autonomia do indivíduo para a adaptação à sociedade; da qualidade para a quantidade; da cultura geral para a cultura profissional. A ênfase do processo educacional estava fortemente direcionada às finalidades da educação, aos ideais e passou a priorizar os meios: metodologias, teleensino, ensino à distância e outros.

Para a formação dos professores, a lei 5.692/71 minimizou a escola normal, tornando-a apenas uma habilitação profissional do ensino secundário.

A Lei 5.692/71 (...) contemplou a escola normal e, no bojo da profissionalização obrigatória adotada para o segundo grau, transformoua numa das habilitações desse nível de ensino, abolindo de vez a profissionalização antes ministrada em escola de nível ginasial. Assim, a 
já tradicional escola normal perdia status de "escola" e, mesmo de "curso", diluindo-se numa das muitas habilitações profissionais do ensino de segundo grau, a chamada Habilitação Específica para o Magistério (HEM). Desapareciam os Institutos de Educação e a formação de especialistas e professores para o curso normal passou a ser feita exclusivamente nos cursos de Pedagogia (TANURI, 2000, p. 80)

A lei 5.692/71 estabeleceu uma determinação mínima de formação para o exercício do Magistério que era: séries);

. Para atuação no ensino de $1^{\mathrm{o}}$ grau $-1^{\mathrm{a}}$ a $4^{\mathrm{a}}$ série: habilitação em nível $2^{\mathrm{o}}$ grau (três

. Para atuação no ensino de $1^{\mathrm{o}}$ grau $-1^{\mathrm{a}}$ a $8^{\mathrm{a}}$ série: curso de licenciatura curta no Ensino Superior; Superior.

- Para atuação no ensino de $1^{\circ}$ e $2^{\circ}$ graus: curso de licenciatura plena no Ensino

Foram criados, ainda, os estudos adicionais de um ano, em instituições de ensino superior para habilitar os egressos de segundo grau ao exercício de docência até $6^{\mathrm{a}}$ série do primeiro grau e os egressos de cursos de licenciatura curta à docência até a $2^{\mathrm{a}}$ série do ensino de segundo grau.

O currículo da Habilitação Específica para o Magistério (HEM) era constituído por um núcleo comum de formação geral e uma parte de formação especial, incluindo Fundamentos da Educação, Estrutura e Funcionamento do Ensino de $1^{\circ}$ Grau, Didática e Prática de Ensino.

Refletindo a lógica da fábrica que, no modelo taylorista-fordista, estabelecia uma divisão social e técnica do trabalho marcada pela definição de fronteiras entre as ações intelectuais e instrumentais, em decorrência de relações de classe bem definidas que determinam as funções a serem exercidas por dirigentes e trabalhadores no mundo da produção, o tecnicismo no contexto escolar, resultou em processos educativos que separavam a teoria da prática. Isso ficou posto no fracionamento possibilitado pela legislação na formação em habilitações compartimentadas para o magistério em escolas maternais e jardins de infância; magistério em turmas de $1^{\mathrm{a}}$ e $2^{\mathrm{a}}$ séries; magistério em $3^{\mathrm{a}} \mathrm{e}$ $4^{\mathrm{a}}$ séries; magistério em $5^{\mathrm{a}}$ e $6^{\mathrm{a}}$ séries, entre outras habilitações possíveis. Conforme Tanuri (2000, p. 81), essa fragmentação fez com que se reduzisse a carga horária destinada às disciplinas pedagógicas, levando à descaracterização e perda da identidade da escola normal.

\subsection{A contemporaneidade: $o$ neoliberalismo vinculado ao neotecnicismo}

De acordo com Hilsdorf (2003), o período das décadas de 1.980 e 1.990 vem sendo chamado pelos analistas como o "das décadas perdidas". Isto posto, considerando-se que não houve melhoria no padrão de distribuição de renda para o todo da sociedade brasileira.

Houve crescimento econômico, de alguns setores, mas também um regime inflacionário permanente e um permanente e um significativo processo de concentração de rendas, de propriedade, de capital e, de mercado. Nos anos 90 o país cresceu menos ainda e aumentou o desemprego em relação aos anos 80: os autores concordam que o controle da inflação foi obtido em troco de uma grave crise social (HILSDORF, 2003 p. 127).

No que concerne à formação de professores, tão desvalorizada na proposta da 
legislação anterior, houve uma discussão no sentido de revitalizar o ensino normal, destacando-se como uma das propostas para a referida revitalização a criação dos Centros de Formação e Aperfeiçoamento do Magistério (CEFAM) ${ }^{6}$.

O CEFAM é caracterizado como uma Escola Normal, cuja função é a preparação do professor para a docência na pré-escola e quatro séries iniciais do ensino de $1^{\circ}$ grau, sendo responsável, pela formação do novo profissional e aperfeiçoamento dos profissionais em exercício no Magistério. Fica explicitada a preocupação com a qualidade da formação do professor na proposta de trabalho do CEFAM, ao descrever que o centro deverá contribuir para a qualificação de um profissional com competência técnica e política capaz de responder com presteza às novas demandas exigidas pelas camadas populares que são, em sua maioria, a clientela da escola pública ( PIMENTA, 2010 p. 127).

Entre as ações propostas para a melhoria da formação de professores, destacou-se ainda, a reformulação do Curso de Pedagogia, dando maior ênfase à preparação do professor para as séries iniciais do ensino fundamental.

Em meio a um período de reestruturação do sistema capitalista, marcado pelo modelo produtivo da fábrica, numa visão toyotista - na qual os sistemas hierarquizados e integrados verticalmente no modelo fordista, cedem lugar a sistemas flexíveis integrados horizontalmente, cuja ótica é a produtividade: produzir mais em menos tempo , sem desperdício, tendo o foco no desenvolvimento tecnológico - fez-se necessário pensar uma escola para formar um trabalhador que atendesse as necessidade desse mercado.

Algumas mudanças são identificadas nos discursos e nas práticas escolares, como o combate de toda forma de desperdício através das ferramentas de qualidade total ou a concepção do administrador escolar como "gestor de negócios", através de uma reedição da dimensão empresarial da gestão escola.

Nesse contexto, é criada a Lei 9.394/96, referenciando a educação para a formação de um trabalhador com boa qualificação que dê suporte a produtividade; um trabalhador flexível e multifuncional, com competência e habilidades previstas para garantir sua inserção no mercado de trabalho, ou seja, sua empregabilidade. Esse foco na formação de trabalhadores, suplantando a formação de cidadãos e a busca pela produtividade e qualidade, estariam configurando uma retomada ao tecnicismo sob novas bases, o que configuraria um neotecnicismo.

No que diz respeito à formação de professores, a LDB 9.394/96 estabelece a regra e a exceção, uma vez que, do ponto de vista do artigo $n^{\circ} 62$ da LDB 9.394/96, a formação de professores para a educação básica deve acontecer em nível superior, em curso de licenciatura, de graduação plena, em universidades e institutos superiores de educação; em seu artigo de número 63, estabelece que os Institutos Superiores de Educação deverão manter cursos formadores de profissionais para a educação básica, inclusive o curso normal superior, destinados à formação de docentes para a educação infantil e para as primeiras séries do ensino fundamental. Entretanto, na mesma medida em que estabelece como regra a formação de professores para a Educação Básica em nível superior, admite como formação mínima a oferecida em nível médio, nos cursos normais. As sobreposições de funções nos cursos de Pedagogia e Normal Superior, bem como a dissociação entre ensino, pesquisa e extensão nos Institutos Superiores de Educação causam preocupação sobre a qualidade da formação de professores possibilitada pela legislação vigente.

Tudo indica que, apesar da conquista legal, a formação em nível superior continua a ser um desafio para os educadores, até porque a recente regulamentação dos Institutos Superiores de Educação (Res. CNE 1/99) tem trazido incertezas acerca de suas conseqüências para a qualificação de docentes. Por parte de educadores, de instituições de ensino superior e 
de associações de docentes, embora se reconheça que eles podem ser um avanço nos locais onde inexistem cursos superiores de formação, teme-se um nivelamento por baixo em face da ênfase numa formação eminentemente prática, desvinculada da possibilidade de pesquisa, e devido aos padrões de qualificação docente inferiores àqueles exigidos nas universidades (TANURI, 2000, p.85).

Com a abertura aos Institutos Superiores de Educação o Estado neoliberal delega ao setor privado a maior parte de suas obrigações em relação à formação de professores, deixando, como afirma Hilsdorf (2003, p.132) que os interesses do mercado definam os objetivos, as instituições e os valores da sociedade.

\section{Considerações finais}

Ao revisitar aspectos da história da educação no Brasil, de sua historiografia, da legislação do magistério, do contexto social brasileiro e das tendências educacionais que estiveram presentes em cada período da história da educação brasileira, a partir de 1.932, verifica-se a relação entre os processos econômicos e os processos educacionais marcando fortemente a definição dos avanços, das permanências e das rupturas verificáveis em cada período revisto.

Em linhas bastante gerais, este exercício de pesquisa e reflexão nos possibilitou lançar um olhar sobre o ensino nacionalista das décadas de 1.930 e 1.940, que sustentou a tendência escolanovista, focada na valorização da cultura nacional como fundamento da formação de uma nova pátria; o desenvolvimentismo-nacionalista das décadas de 1.950 e 1.960 que pouco trouxe de inovação em relação às décadas anteriores, a não ser a inserção dos movimentos de bases populares, na maioria das vezes apoiados pela Igreja Católica e intelectuais, que lançaram as bases da tendência da Educação Libertária; a década de 1.970, marcada pelo desenvolvimentismo da indústria, que focou a educação técnica para a formação de um trabalhador capaz de acompanhar o grau tecnológico das empresas e, finalmente, na contemporaneidade, viu-se novamente o mercado dominando a formação do trabalhador, numa retomada, em forma de releitura, à perspectiva da teoria do "capital humano", empregada na década de 1.970, focando a educação com função de habilitar as pessoas a competir no mercado de trabalho.

As permanências mais significativas que observamos, ao revisitar a trajetória do processo de formação de professores, foi a descontinuidade das políticas educacionais, a minimização do estado e o foco na quantidade e não, na qualidades dos processos de formação.O excessivo número de reformas educacionais, especialmente no que concerne à formação docente, não permitiu o estabelecimento de um programa consistente de formação de professores, capaz de atuar na área de formação integral do aluno e do profissional da educação. Essas reformas - focadas na melhoria da qualidade do ensino, na universalização do ensino fundamental e superação do analfabetismo - tiveram problemas de implementação e continuidade ou simplesmente pereceram pela falta de programas de financiamento, tornando-se metas constantemente adiadas para um novo plano de educação. Um exemplo comprobatório dessa afirmação é a formação de professores, que desde 1.962 está fixada para ocorrer em nível superior e até os dias atuais é permitida em nível médio.

Pesa ainda, sobre o processo de formação de professores a desresponsabilização do Estado com a formação de professores, que transfere grande parte de sua tarefa para os Institutos Superiores de Educação, entidades que não aliam ensino, pesquisa e extensão e acabam por estimular e promover uma formação focada na quantidade e não na qualidade 
dos profissionais que formam.

A falta de uma política de formação de professores, com o estabelecimento de um padrão adequado para a preparação docente se apresenta como fator complicador para a melhoria tão destacada pelas reformas educacionais, para a qualidade da educação no país.

Repensar, pois, a formação dos professores deveria ser o grande desafio para as políticas educacionais, tema que não pode estar desvinculado da valorização profissional.

\section{Referências}

BRASIL. Lei 9.394 de 20 de dezembro de 1996. Dispõe sobre as Diretrizes e Bases da Educação Nacional. Brasília: MEC, 1996.

Lei $n^{0}$ 4.024 de 20 de dezembro de 1961. Fixa as Diretrizes e Bases para a Educação Nacional. Disponível em: <http://www.jusbrasil.com.br/legislacao/108164/leidediretrizes-e-base-de-1961-lei-4024-61>. Acesso em: 04 abr. 2010.

Lei $n^{0} 5.692$ de 11 de agosto de 1971. Fixa Diretrizes e Bases para o ensino de $1^{\circ}$ e $2^{\circ}$ graus, e dá outras providências. Disponível em: <http://www.planalto.gov.br/ ccivil_03/Leis/L5692.htm>. Acesso em: 04 abr. 2010.

CAVALCANTE, M.J. CEFAM: uma alternativa pedagógica para a formação do professor. São Paulo: Cortez, 1994.

COSTA, Marilia. Enciclopédia de Pedagogia Universitária. Porto Alegre: FAPERGS/RIES, 2003.

DALBEN, Ângela Imaculada Loureiro de Freitas. Conselhos de Classe e Avaliação. Perspectivas na gestão pedagógica da escola. Campinas: Papirus, 2004.

GHIRALDELli Jr, Paulo. A evolução das idéias pedagógicas no Brasil Republicano. Cad. Pesquisa, São Paulo, 1987, v.60, p. 28-37.

HILSDORF, Maria Lucia Spedo. História da Educação Brasileira: Leituras. São Paulo: Cengage Learning, 2003.

KISHIMOTO, Tizuko Morchida. Avanços e retrocessos na formação de profissionais da educação infantil. In: MACHADO, Maria Lucia de (org). Encontros e Desencontros em Educação Infantil. São Paulo: Cortez, 2002, p. 107 - 115.

KUENZER, Acácia Zeneida (org.). A formação dos profissionais da educação: proposta de Diretrizes Curriculares Nacionais. Mimeo. 1998.

MELLO, Guiomar N. de. Formação inicial de professores para a educação básica: uma (re) visão radical. Março, 2000. Disponível em: 〈http://www.namodemello.com.br>. Acesso em 05 abr.2010.

OLIVEIRA, Daniela Motta. A Formação de Professores na Lei 9394/96 - Um estudo comparativo das diretrizes estabelecidas para a formação de professores de Educação Infantil e das séries iniciais do Ensino Fundamental nos anos 70 e nos anos 90. Rio de 
Janeiro, 1998. (Dissertação de Mestrado).

PASCHOAL, Jacqueline Delgado e MACHADO, M. C. Gomes. A história da educação infantil no Brasil. Revista HISTEDBR On-line. Campinas, v. 33, p.78-95. Mar. 2009. Disponível em ISSN: 16762584

SAVIANI, Dermeval. A nova lei da educação: Trajetória, Limites e Perspectivas. Campinas, SP: Autores Associados, 1997.

Dermeval. Da nova LDB ao Novo Plano Nacional de Educação: por uma outra política educacional. Campinas, SP: Autores Associados, 1998.

, Dermeval. História da idéias pedagógicas no Brasil. Campinas, SP: Autores Associados, 2007.

Dermeval. Pedagogia e formação de professores no Brasil: vicissitudes dos dois últimos séculos. IV Congresso Brasileiro de História da Educação - 2008 -UNICAMP

Dermeval. A nova lei da educação (LDB): trajetória, limites e perspectivas. 11. ed. Campinas: Autores Associados, 2008.

Dermeval. A Política Educacional no conjunto das políticas sociais. In. Simpósios da III CBE. São Paulo, Loyola, 1984.

SCHUlTZ, T. Capital Humano. Rio de Janeiro: Zahar, 1973.

SEVERINO, Joaquim Antonio e Fazenda, Ivani A. C. (org) Formação Docente: rupturas e possibilidades. Papirus, 2002.

TANURI, Leonor Maria. História da formação de professores. Revista Brasileira de Educação. nº 14 - maio-junho-julho-agosto, 2000, p. 108-130.

VALENTE, Ivan e ROMANO, Roberto. PNE. Plano Nacional de Educação ou Carta de Intenção? Revista Educação e Sociedade. vol. 23, nº.80, 2002, p. 96-107.

\section{NOTAS:}

\footnotetext{
1 Sandra Regina Rodrigues do Amaral é mestranda do Programa de Pós-Graduação em Educação da Universidade Estadual de Londrina, linha de pesquisa Perspectivas Filosóficas, Históricas e Políticas de Educação. Membro do Grupo de Estudos História e Ensino de História.

2 O "milagre econômico brasileiro" refere-se ao período de 1968 até 1973 no qual a disponibilidade externa de capital e a determinação dos governos militares de fazer do Brasil uma "potência emergente" viabilizaram pesados investimentos em infra-estrutura, nas indústrias de base, de transformação, equipamentos, bens duráveis e na agroindústria de alimentos. Houve, neste período, extraordinárias taxas de crescimento do Produto Interno Bruto (PIB) então verificadas, de 11,1\% ao ano. Uma característica notável do "milagre" é que o rápido crescimento veio acompanhado de inflação declinante e relativamente baixa para os padrões brasileiros, além de superávits no balanço de pagamentos. A literatura pertinente não consensua sobre o tema, atribuindo o "milagre" ora à políticas monetária e creditícia expansionistas e os incentivos às exportações, ora ao ambiente externo favorável ocasionado pela expansão da economia internacional ou ainda às reformas fiscais/tributárias e financeira promovidas pelo governo Castelo Branco, que teriam dotado o país de condições para o crescimento.
} 
3 A Ação Integralista Brasileira (AIB), foi um partido político brasileiro, fundado pelo jornalista Plínio Salgado em 1932, com o "Manifesto de 1932", que defendia um Estado autoritário. Foi um partido, apoiado por Getúlio Vargas que iniciou suas atividades influenciado pelo fascismo italiano. Entretanto, em 1937 Vargas proíbe a existência de qualquer partido político, o que ocasiona em 1938 um levante da AIB contra o seu governo. O movimento ficou conhecido como "Levante Integralista". A Aliança Nacional Libertadora (ANL) Organização política de âmbito nacional fundada oficialmente em 1935, tinha como objetivo combater o fascismo e o imperialismo. Seu Presidente de honra e maior exponte foi Luís Carlos Prestes, que na época encontrava-se na União Soviética e havia aderido ao comunismo. O programa da ANL tinha como pontos principais a suspensão do pagamento da dívida externa do país, a nacionalização das empresas estrangeiras, a reforma agrária e a proteção aos pequenos e médios proprietários, a garantia de amplas liberdades democráticas e a constituição de um governo popular.

${ }^{4}$ Refere-se ao período da História do Brasil conhecido como "Estado Novo" (1937-1945).O Estado Novo foi implantado por Getúlio Vargas em 1937, a partir de um golpe de estado, sob a justificativa de conter uma nova ameaça de golpe comunista no Brasil. Para dar ao novo regime uma aparência legal, Francisco Campos, aliado político de Getúlio, redigiu uma nova constituição inspirada por itens das constituições fascistas italiana e polonesa, que continha vários artigos com características anti-democráticas.

${ }^{5}$ Schultz (1973) define o 'capital humano' como o montante de investimento em habilidades e conhecimentos que uma nação ou indivíduos fazem na expectativa de retornos adicionais futuros. Para Schultz, o fator $\mathrm{H}$ (capital humano) passou a compor a função de produção da teoria econômica marginalista para explicar os diferenciais de desenvolvimento entre países e entre indivíduos. Deste modo,o nível de desenvolvimento maior ou menor entre países ou a mobilidade social dos indivíduos que se explicavam por A (nível de tecnologia), K (insumos de capital) e L (insumos de mão-de-obra) passaram a receber um novo componente: o fator $\mathrm{H}$. Este seria potenciador do fator L. Países que investissem mais no fator $\mathrm{H}$ teriam a chave para sair de sua condição de subdesenvolvidos para desenvolvidos.

${ }^{6}$ O CEFAM (Centro de Formação e Aperfeiçoamento do Magistério) surgiu na década de 80 do século XX, enquanto uma iniciativa do MEC, elaborado pela antiga Coordenadoria do Ensino Regular de Segundo Grau para revitalização do ensino normal, que fora diluído em apenas uma habilitação do ensino de $2^{\circ}$ grau (HEM), pela Lei 5692/71. O CEFAM foi criado conforme esclarece Cavalcante (1994) com o objetivo de redimensionar as escolas normais, dotá-las de condições adequadas à formação dos profissionais com competência técnica e política; e ampliar-lhes as funções, de modo a torná-las um centro de formação inicial e continuada para professores de educação pré-escolar e para o ensino de séries iniciantes.

Recebido em: $\quad 26 / 08 / 10$

Aprovado em: 15/03/11 